\title{
Investigation of the hygienic safety of aromatic plants cultivated in soil contaminated with Listeria monocytogenes
}

\author{
Luca Settanni $^{\mathrm{a}, *}$, Alessandro Miceli ${ }^{\mathrm{b}}$, Nicola Francesca ${ }^{\mathrm{a}}$, Giancarlo Moschetti ${ }^{\mathrm{a}}$ \\ a DEMETRA Department, University of Palermo, Viale delle Scienze 4, 90128 Palermo, Italy \\ ${ }^{\mathrm{b}}$ SAGA Department, University of Palermo, Viale delle Scienze 4, 90128 Palermo, Italy
}

\section{A R T I C L E I N F O}

\section{Article history:}

Received 21 October 2011

Received in revised form

9 January 2012

Accepted 17 January 2012

\section{Keywords:}

Basil

Hygienic safety

Listeria monocytogenes

Microbial transfer

Rocket

Soil

\begin{abstract}
A B S T R A C T
The present work was undertaken to investigate the survival of Listeria monocytogenes ATCC $19114^{\mathrm{T}}$ in soil during the whole crop cycle of rocket (Eruca sativa Mill.) and basil (Ocimum basilicum L.), to monitor its transfer to the leaves, and to evaluate its viability at harvest. To this purpose, the soil was $\mathrm{N}-\mathrm{P}-\mathrm{K}$ fertilized and four trials, obtained with different combinations of soil treatment, listerial inoculums and seed planting, were followed for each aromatic plant. Soil was weekly investigated for total microbial counts and L. monocytogenes evolution. At the starting time, un-inoculated autoclaved soil showed a limited microbial load $\left(10^{3} \mathrm{CFU} \mathrm{g} \mathrm{dw^{-1 }}\right)$, while un-inoculated non-autoclaved soil contained approximately $10^{8} \mathrm{CFU} \mathrm{g} \mathrm{dw}{ }^{-1}$ microorganisms. Listerial persistence in inoculated soil was evaluated by plate counts and confirmed by randomly amplified polymorphic DNA (RAPD) analysis. Trials with nonautoclaved un-inoculated soil, used as control productions, contained about $10^{4} \mathrm{CFU} \mathrm{g} \mathrm{dw}^{-1}$ of presumptive Listeria spp., from the beginning till the end of the experimentation, which lasted six weeks.

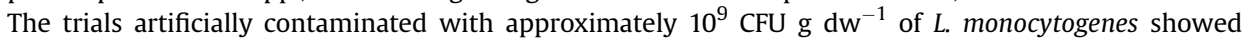
a decrease of the initial inoculums, which was more rapid, reaching lower levels at harvest, for the trials with non-autoclaved soil (4.95 and $4.81 \log$ CFU g dw ${ }^{-1}$ for basil and rocket, respectively) than those with autoclaved soil (5.28 and $5.24 \log$ CFU g dw ${ }^{-1}$ for basil and rocket, respectively). At harvest, plants and soil samples were also analysed by denaturing gradient gel electrophoresis (DGGE). The last analysis showed the presence of $L$. monocytogenes in soil, but not on the leaves of plants of all inoculated trials. (C) 2012 Elsevier Ltd. All rights reserved.
\end{abstract}

\section{Introduction}

Consumers' demand for fresh-cut vegetables, mainly in form of salad, underwent a massive increase in the last years. Several factors affected this phenomenon: the food policies of many Countries encouraging healthy diets; the high convenience of use; the image of lightness associated with salad consumption. The request for this type of food is still on the increase, especially by people consuming light meals during work breaks or among singles or small families, as well as by caterings. Fresh-cut salads may be prepared with one or several ingredients, varying according to the season or the geographical traditions. Some vegetable salads are world-wide available, whereas some recipes are typical of a given area.

Rocket (Eruca sativa Mill.) is a leafy vegetable that belongs to the Cruciferous family and is originated in the Mediterranean region,

\footnotetext{
* Corresponding author. Tel.: +39091 23896043; fax: +39 0916515531.

E-mail address: luca.settanni@unipa.it (L. Settanni).
}

but widely distributed all over the world. Like other cruciferous vegetables, rocket contains a range of health-promoting phytonutrients including vitamin C, fibre, flavonoids and glucosinolates (Martínez-Sánchez, Allende, Bennett, Ferreres, \& Gil, 2006). It has a rich, peppery taste, and an unusually strong flavour for a leaf vegetable. The leaves are eaten raw in salads (often mixed with other greens or mushrooms) or cooked in various culinary preparations, and are grown or gathered from wild plants in many parts of the world (Bianco, 1995). In Italy, rocket is often used in pizzas, added immediately afterwards the baking period ends, so that it will not wilt in the heat. Lately, the rocket market has grown impressively thanks to its consumption in many European Countries also as a fresh-cut product (D'anna, Miceli, \& Vetrano, 2003). Basil (Ocimum basilicum L.) is native to Asia, Africa, South America, and the Mediterranean Basin, but widely cultivated in many Countries. It is a very important medicinal plant and culinary herb marketed fresh, dried, or frozen. Sweet basil contains phenolic compounds and flavonoids that are potent antioxidants, free radical scavengers, and metal chelators (Jayasinghe, Gotoh, Aoki, \& Wada, 2003). It has long been prized for its foliage, which adds 
a distinctive flavour to many foods. Basil is used fresh in salads in many Countries, especially in the Mediterranean area. In Italy, it is often associated with mozzarella and tomato salads, easily available in bars and restaurants. Rocket and basil are widely cultivated and often grown at home in pots or garden for daily uses.

Sources of microbial pathogens on vegetables at the pre-harvest stage include feaces, irrigation water, inadequately composted manure, soil, air, animals, and human handling (Beuchat, 1996; Buck, Walcott, \& Beuchat, 2003). The microbial safety of vegetables may be further compromised during harvest, transport, processing and storage (Martínez-Sánchez et al., 2006). However, especially for leafy vegetables, if leaves do not undergo an intense washing treatment, soil contamination plays a defining role on the hygienic characteristics of the product. This is particularly dangerous for consumers' health when the irrigation is performed with raw or treated, diluted or un-diluted, wastewater, since it may host several microbial pathogens (Hamilton et al., 2005; Toze, 2006). The demand for water by agriculture in Europe has increased during recent decades as a result of growing populations and altered precipitation patterns (Forslund et al., 2010). The increasingly limited water supplies calls for alternative solutions and the European Water Framework Directive (2000/60/EC) encourages and promotes the use of treated urban wastewater in agriculture. This agronomic practice is becoming common; it occurs in many Countries (Scott, Faruqui, \& Raschid-Sally, 2004) because it is of high-value for the horticultural crops.

Recently, fresh-cut products that are consumed raw have been increasingly linked to food-borne outbreaks (DeWaal \& Bhuiya, 2007; Sivapalasingam, Friedman, Cohen, \& Tauxe, 2004). Thus, the absence of pathogenic microorganisms on leafy vegetables used to prepare salads is crucial. Bacterial pathogens mainly associated with vegetable salad foods are Listeria monocytogenes, Salmonella enterica, Bacillus cereus and Escherichia coli (Beuchat \& Ryu, 1997; Breer \& Baumgartner, 1992; Cordano \& Jacquet, 2009; Little et al., 2007; Militello et al., 2011; Sagoo, Little, Ward, Gillespie, \& Mitchell, 2003; Valero, Hernández-Herrero, \& Giner, 2007). L. monocytogenes is often found in mixed salads, such as mozzarella salad or rice salad (Militello et al., 2011). The last bacterium has been recognized as an emerging agent of food-borne diseases (Farber, 2000). Although listeriosis has a very low incidence, it shows a high case fatality rate that can exceed $30 \%$ (Drevets \& Bronze, 2008). Recently, several European countries are experiencing an apparently increasing incidence of this disease, mainly amongst persons aged 65 years and older (Goulet, Hedberg, Le Monnier, \& de Valk, 2008).

The objectives of the present study were: to investigate the survival of L. monocytogenes in soil during the whole crop cycle of rocket and basil; to monitor its transfer to the leaves; and to evaluate its viability on the leaf surface at harvest.

\section{Materials and methods}

\subsection{Plant material and microbial strain}

Seeds of rocket (E. sativa Mill.) and basil (O. basilicum L.) were purchased from Blumen (Milan, Italy). L. monocytogenes ATCC $19114^{\mathrm{T}}$ was propagated in Brain Heart Infusion (BHI) (Oxoid, Milan, Italy) at $37{ }^{\circ} \mathrm{C}$ for $24 \mathrm{~h}$. The experimental plan included four different conditions for each plant crop, forming a total of eight trials: ASB, autoclaved soil planted with basil; nASB, nonautoclaved soil planted with basil; ASLB, autoclaved soil inoculated with L. monocytogenes ATCC $19114^{\mathrm{T}}$ and planted with basil; nASLB, non-autoclaved soil inoculated with $L$. monocytogenes ATCC $19114^{\mathrm{T}}$ and planted with basil; ASR, autoclaved soil planted with rocket; nASR, non-autoclaved soil planted with rocket; ASLR, autoclaved soil inoculated with L. monocytogenes ATCC $19114^{\mathrm{T}}$ and planted with rocket; nASLR, non-autoclaved soil inoculated with L. monocytogenes ATCC $19114^{\mathrm{T}}$ and planted with rocket. Eight replicate pots were produced for each trial. Two independent experiments were performed in two consecutive days.

\subsection{Soil inoculation and plant growth}

Commercial soil Spezial-substrat (Floragard GmbH, Oldenburg, Germany) composed of a mixture of slightly or fully decomposed raised bog peat ( $\mathrm{pH} 5.6)$ was fertilized with $2 \%$ o $\mathrm{w} / \mathrm{v}$ ) of nitrophoska blue (COMPO GmbH \& Co., Münster, Germany) before pots (Ø $8 \mathrm{~cm})$ were filled in. A part of the bulk soil was autoclaved (60 min at $121{ }^{\circ} \mathrm{C}$ ) in aluminium boxes (250-mL volumes) for the thermal treated trials. Prior inoculation, the fresh culture (developed overnight) of L. monocytogenes was centrifuged at 10,000 $\times g$ for 5 min, washed in Ringer's solution (Sigma-Aldrich, Milan, Italy) and re-suspended in the same solution till reaching an optical density (OD) of ca. 1.00, measured by 6400 Spectrophotometer (Jenway Ltd., Felsted Dunmow, UK) at $600 \mathrm{~nm}$ wavelength, which approximately corresponds to a concentration of $10^{9} \mathrm{CFU} \mathrm{mL}{ }^{-1}$. Cell suspension was added to the soil in the ratio $1: 10(\mathrm{v} / \mathrm{v})$; a vigorous mixing was performed by means of a sterile spoon in order to ensure the homogenous distribution in the whole soil volume. After mixing the different combinations of soil and inoculums, pots (250 mL of soil volume, corresponding approximately to $100 \mathrm{~g}$ weight) were filled in. Ten seeds of basil or rocket were sown for each pot. Pots were daily watered from below (sub-irrigation) with sterile water, in order to avoid further microbial contamination to the soil and kept at $20^{\circ} \mathrm{C}$ till seed germination.

After seed emergence, pots were transferred in an unheated plastic greenhouse (SAGA Department - University of Palermo, Italy), where basil and rocket plants were grown during spring 2011, leaving only four plants per pot. Each pot received the same volume of water that varied daily according to environmental conditions and plant needs till harvesting.

\subsection{Sample collection}

The sampling plan included both soil and plants with two replications ( 2 pots) for each trial:

a) soil was sampled randomly at the time of pot filling $\left(T_{0}\right)$ and at 7-day intervals. Aliquots of approximately $10 \mathrm{~g}$ of soil from each pot, till a depth of ca. $5 \mathrm{~cm}$ from the surface, were aseptically collected by means of a portable Bunsen, alcohol-sanitized gloves and sterilized spoons and, then, transferred into sterile plastic bags;

b) plants were collected at two distinct time: at emergence (seedlings with cotyledons and part of the hypocotyl) and at harvest. Sterile dissecting scissors and tweezers were used to transfer the randomly collected vegetable material into the sterile plastic bags.

\subsection{Microbiological analysis}

Microbiological analyses were performed after decimal serial dilution of soil ( $10 \mathrm{~g})$ and plant $(10 \mathrm{~g}$ at harvest and $2 \mathrm{~g}$ for seedlings) samples. Except the first dilution of soil, which was carried out with sodium pyrophosphate $(0.16 \% \mathrm{w} / \mathrm{v})$ solution to break down the aggregates and dislodge microbial cells, all dilutions were performed in Ringer's solution. The homogenization of soil was obtained in sterile flasks shacked for $10 \mathrm{~min}$ at $150 \mathrm{rpm}$, while plants were homogenized in a Laboratory Blender Stomacher 400 
(Seward, London, UK) for 2 min at the highest speed. Microbial suspensions were plated and incubated as follows: total mesophilic count (TMC) on Plate Count Agar, incubated aerobically at $30^{\circ} \mathrm{C}$ for $72 \mathrm{~h}$; presumptive Listeria spp. on Listeria Selective Agar Base (LSAB) supplemented with SR140 (Oxford formulation), incubated aerobically at $37{ }^{\circ} \mathrm{C}$ for $48 \mathrm{~h}$. Microbiological counts were performed in duplicate.

The samples negative for direct detection of listerial cells were subjected to a multi-step enrichment procedure before plating: i) primary selective enrichment in Half Fraser Broth (HFB) which included $25 \mathrm{~g}$ of sample in $225 \mathrm{~mL}$ HFB for soil, $10 \mathrm{~g}$ in $90 \mathrm{~mL}$ HFB for plants and $2 \mathrm{~g}$ in $18 \mathrm{~mL}$ HFB for seedlings, incubated at $30^{\circ} \mathrm{C}$ for $24 \mathrm{~h}$; ii) secondary selective enrichment in Fraser Broth $(10 \mathrm{~mL})$ inoculated with $0.1 \mathrm{~mL}$ of primary enriched culture, incubated at $37{ }^{\circ} \mathrm{C}$ for $48 \mathrm{~h}$. Ten microlitres of the secondary enriched culture were then streaked onto supplemented LSAB and the incubation was as reported above. Primary and secondary selective enrichments were conducted following the indications ISO 11290-1.

All media and supplements were purchased from Oxoid.

Data from bacterial counts of the two independent experiments were averaged and converted to $\log \mathrm{CFU} \mathrm{g}{ }^{-1}$ dry weight (dw) for soil samples and to $\log$ CFU g ${ }^{-1}$ for plant samples. Moisture content of soil samples was determined by drying approximately $5 \mathrm{~g}$ of soil, from each pot at each sample time, at $105 \pm 1^{\circ} \mathrm{C}$ for $24 \mathrm{~h}$ in a drying oven and weighting the residual.

Analysis of variance (ANOVA), elaborated with the program SPSS 14.0 (SPSS Inc., Chicago, IL, USA), was performed. Significance level $P<0.05$. Duncan's multiple range test was used to determine differences among microbial population on the plants of the different trials.

\subsection{Recognition of L. monocytogenes ATCC $19114^{T}$}

All colonies developed onto LSAB surface, at the highest dilution of sample suspensions, were picked up from agar plates and cultured in BHI overnight at $37^{\circ} \mathrm{C}$. The cultures were purified to homogeneity by successive sub-culturing onto BHI agar and kept at $-80{ }^{\circ} \mathrm{C}$ in glycerol $(20 \%, \mathrm{v} / \mathrm{v})$ stocks. The isolates and L. monocytogenes ATCC $19114^{\mathrm{T}}$ were analysed by randomly amplified polymorphic DNA-PCR (RAPD-PCR). DNA from broth cultures was extracted by the Instagene Matrix kit (Bio-Rad, Hercules, CA) as described by the manufacturer. Crude cell extracts were used as template for PCR reactions. RAPD-PCR was performed by means of T1 Thermocycler (Biometra, Göttingen, Germany) using the primer M13 (Stenlid, Karlsson, \& Hogberg, 1994). Amplifications were performed applying the conditions reported by Zapparoli, Torriani, and Dellaglio (1998). PCR products were separated by electrophoresis on $1.5 \%(\mathrm{w} / \mathrm{v})$ agarose gel (Gibco BRL, Cergy Pontoise, France) and visualized by UV transillumination after staining with ethidium bromide $\left(0.5 \mu \mathrm{g} \mathrm{mL}{ }^{-1}\right)$. O'gene Ruler ${ }^{\mathrm{TM}}$ DNA ladder Mix (Medical Srl, Milan, Italy) was used as a molecular size marker.

\subsection{Culture-independent detection of L. monocytogenes in soil and plant samples}

At harvest, plant and soil samples were also analysed by denaturing gradient gel electrophoresis (DGGE). This technique was applied to reveal the presence of accessible DNA of no more viable $L$. monocytogenes in the samples resulted negative for listerial presence after the enrichment procedure. The samples were diluted as reported above for microbiological analysis and $500 \mathrm{mg}$ of pellet, obtained after centrifugation at $10.000 \times g$ for $5 \mathrm{~min}$, were used for total DNA extraction performed with the FastDNA ${ }^{\circledR}$ Pro Soil-Direct Kit (MP Biomedicals, CA, USA) following manufacturer's instructions. Bacterial DNA was amplified with the primer pair GC-
HDA1/HDA2 (Walter et al., 2000). PCRs were carried out as reported by Giannino, Marzotto, Dellaglio, and Feligini (2009) using the T1 Thermocycler (Biometra, Göttingen, Germany). The amplicons were run in polyacrilamide gels ( $20 \mathrm{~cm} \times 20 \mathrm{~cm} \times 1 \mathrm{~mm}$ ) by means of the Phor-U2 system (Ingeny, Leiden, The Netherlands). Gels were prepared with $6 \%(\mathrm{w} / \mathrm{v})$ polyacrylamide [acrylamide/bisacrylamide (37:1)] in a $1 \times$ TAE [ $40 \mathrm{mM}$ Tris, $20 \mathrm{mM}$ acetic acid, and $1 \mathrm{M}$ EDTA (pH 8.0)] buffer with a $30-60 \%$ denaturing gradient [ $100 \%$ denaturant corresponding to $7 \mathrm{M}$ urea and $40 \%(\mathrm{v} / \mathrm{v}$ ) deionised formamide] increasing in the direction of electrophoresis. Electrophoresis was performed in $1 \times \mathrm{TAE}$ at $60{ }^{\circ} \mathrm{C}$ for $14 \mathrm{~h}$. After runs, gels were stained in a $\mathrm{AgNO}_{3}(0.2 \%, \mathrm{w} / \mathrm{v})$ solution (Niessen, Mcleod, \& Yates, 2005) and captured by Gel Doc 2000 (Bio-Rad).

\section{Results}

\subsection{Plant growth}

Seed germination and seedling emergence occurred after three days from sowing for rocket and seven days for basil. Both soil inoculation and soil autoclaving had no effect on seed germination and plant growth. Average maximum and minimum temperatures inside the greenhouse during the cultivation period ranged between 33.5 and $16.1{ }^{\circ} \mathrm{C}$, respectively. Soil temperature did not differ from air temperature due to the small volume of the pots. After 42 days from sowing, plants were ready for harvesting: basil reached about $25 \mathrm{~cm}$ height and rocket had about 10 leaves per plant.

\subsection{Microbiological analysis}

\subsubsection{Analysis of soil}

The evolution of TMC in the soil of the un-inoculated and artificially contaminated trials are reported in Fig. 1, which also reports the results on the investigation of the presence of presumptive Listeria spp. in the control (un-inoculated) trials (Fig. 1A and C) and the persistence of $L$. monocytogenes ATCC $19114^{\mathrm{T}}$ in the inoculated trials (Fig. 1B and D).

At the beginning of the observation, the un-inoculated nonautoclaved trials contained a TMC of $7.96 \log \mathrm{CFU} \mathrm{g} \mathrm{dw}{ }^{-1}$, while the inoculation of L. monocytogenes ATCC $19114^{\mathrm{T}}$ determined a significant $(P<0.05)$ increase of TMC concentration of about one order of magnitude higher. Regarding presumptive Listeria spp., the initial counts were $4.64 \log$ CFU g dw ${ }^{-1}$ for un-inoculated non-autoclaved trials, while no presumptive Listeria spp. was detected for uninoculated autoclaved trials.

In general, the trials conducted with basil and rocket displayed similar trends with or without $L$. monocytogenes ATCC $19114^{\mathrm{T}}$ inoculation. TMC of each trial carried out with non-autoclaved soil (nASB, nASR, nASLB and nASLR) remained almost constant during the six weeks of experimentation. Instead, TMC estimated for the trails with autoclaved soil showed a different trend among uninoculated and inoculated pots: the former (ASB and ASR) displayed an increasing level from almost $3.02 \log \mathrm{CFU} \mathrm{g} \mathrm{dw}{ }^{-1}$ at T0 to approximately $8.0 \mathrm{log}$ CFU $\mathrm{g} \mathrm{dw}^{-1}$ at the third week, which remained nearly constant till the sixth week, while the concentration levels registered for the inoculated pots (ASLB and ASLR) decreased of about $1 \log$ CFU g dw ${ }^{-1}$ (from the initial value of $8.95 \log$ CFU g dw ${ }^{-1}$ ) after the first week and showed no significant $(P<0.05)$ fluctuations for the other five weeks.

Listerial counts displayed a different evolution from TMC for all trials followed. ASB and ASR were negative for Listeria spp. presence during the entire period of investigation. Although almost constant concentrations of about $4.5 \mathrm{log}$ CFU g dw ${ }^{-1}$ on average were showed by nASB and nASR during the six weeks, listerial 
A

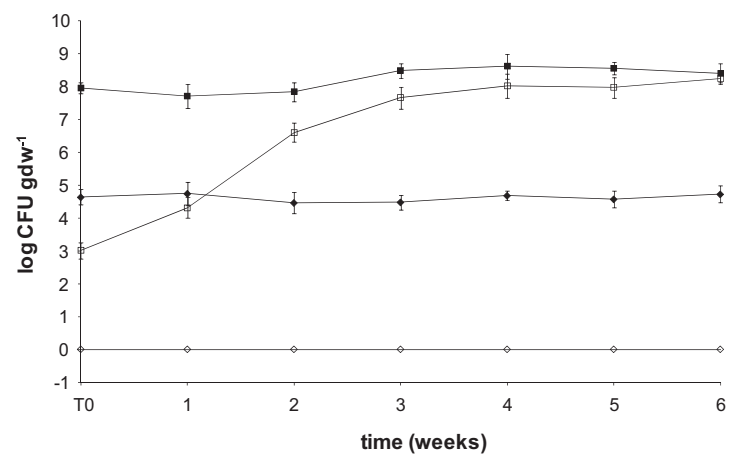

B

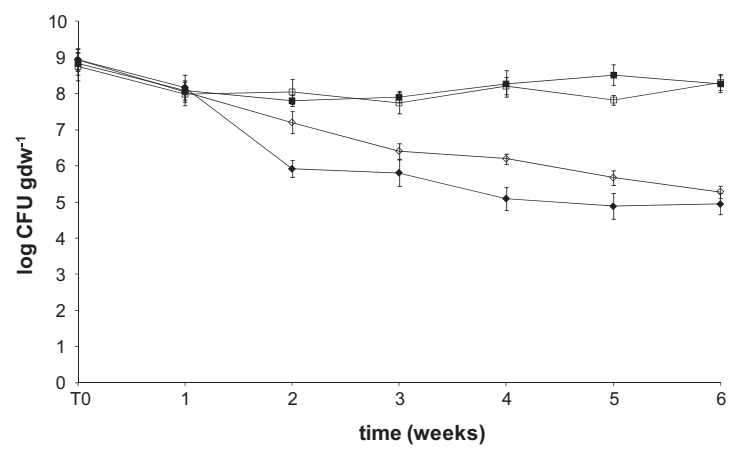

C

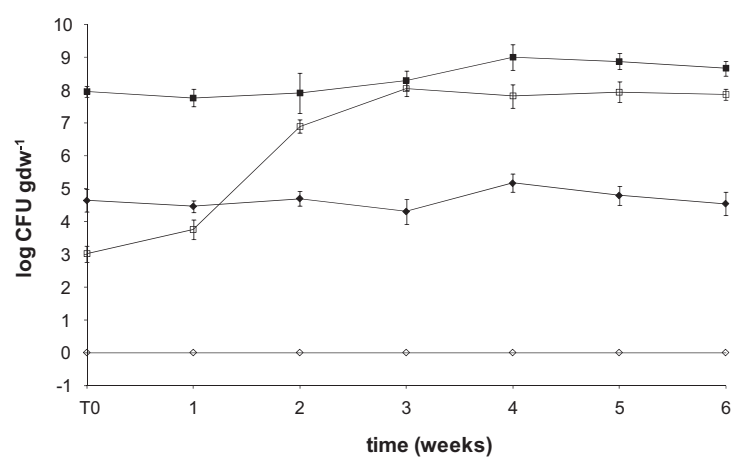

D

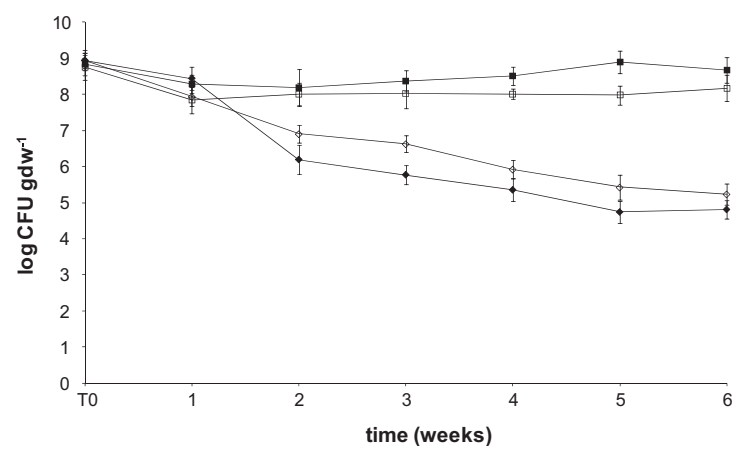

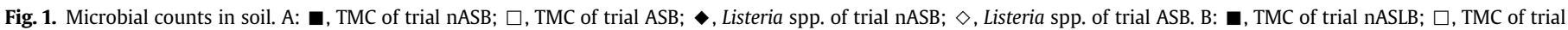

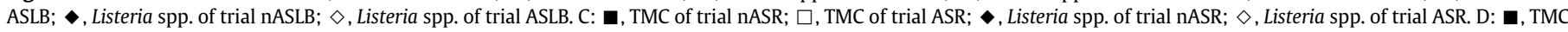

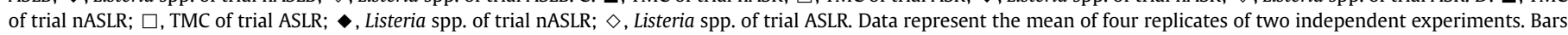
represent standard deviation of the mean. When vertical bars are not visible, they are smaller than symbol size.

counts of the inoculated trials were characterised by a decreasing trend. At the second week, the reduction of listerial concentration observed for nASLB and nASLR trials was higher than that registered for ASLB and ASLR trials. From then on, the reduction observed for non-autoclaved trials was slower than that showed for the corresponding autoclaved soil and no statistical differences of the plate count data were showed by the four trials at the sixth week.

\subsubsection{Analysis of plants}

The plants were analysed for TMC and listerial presence at two distinct moments: soon after emergence (seedlings) and at harvest (Table 1). Seedlings of basil and rocket were collected after 11 and 7 days from sowing, respectively, while the harvest occurred at the sixth week for both plants.

Independently on soil treatment and plant species, seedlings from inoculated trials were characterised by the highest TMC (4.37 $\log$ CFU g ${ }^{-1}$ on average), while all un-inoculated trials showed values lower of about $2 \log$ cycles. Listeria spp. was not detected for ASB and ASR seedlings, while a concentration of ca. $10^{3} \mathrm{CFU} \mathrm{g}^{-1}$ was registered for the corresponding non-autoclaved soil trials. This bacterial genus was found at least at $1 \log$ cycle higher for the four contaminated trials, among which both basil trials showed significantly higher concentration than rocket trials.

TMC for plants at harvest displayed significant differences for the eight trials, which were in the range 3.42-4.48 $\log \mathrm{CFU} \mathrm{g}{ }^{-1}$. Presumptive Listeria spp. detection by direct counting produced negative results for all trials. Thus, the plants of the eight trials were also subjected to the listerial multi-step enrichment procedure before plating, which still produced negative results for presumptive Listeria spp. presence.

\subsection{Differentiation of listerial isolates}

All presumptive listerial isolates were differentiated at strain level by means of RAPD-PCR analysis with primer M13. DNA from L. monocytogenes ATCC $19114^{\mathrm{T}}$ pure culture was included in the analysis in order to a) recognize the added bacterium in soil and on the seedlings of the inoculated trials, b) evaluate the persistence of the same bacterium in soil, c) exclude cross-contamination among

Table 1

Microbiological counts of plants.

\begin{tabular}{|c|c|c|c|c|}
\hline \multirow[t]{3}{*}{ Trial } & \multicolumn{4}{|c|}{ Concentration $\left(\log \mathrm{CFU} \mathrm{g}^{-1}\right)$} \\
\hline & \multicolumn{2}{|l|}{ Seedlings } & \multicolumn{2}{|c|}{ Plants at harvest } \\
\hline & TMC & Listeria spp. & TMC & Listeria spp. \\
\hline ASB & $2.23 \pm 0.12 c$ & od & $3.86 \pm 0.19 b d$ & 0 \\
\hline nASB & $2.35 \pm 0.13 b c$ & $3.24 \pm 0.13 c$ & $3.61 \pm 0.11 \mathrm{de}$ & 0 \\
\hline ASLB & $4.32 \pm 0.22 a$ & $4.50 \pm 0.09 a$ & $3.42 \pm 0.13 \mathrm{e}$ & 0 \\
\hline nASLB & $4.51 \pm 0.10 \mathrm{a}$ & $4.42 \pm 0.18 a$ & $4.12 \pm 0.15 b$ & 0 \\
\hline ASR & $2.46 \pm 0.19 b c$ & od & $3.68 \pm 0.09 c e$ & 0 \\
\hline nASR & $2.62 \pm 0.09 b$ & $3.07 \pm 0.17 c$ & $4.00 \pm 0.12 b c$ & 0 \\
\hline ASLR & $4.36 \pm 0.18 a$ & $4.02 \pm 0.08 b$ & $3.58 \pm 0.15 \mathrm{de}$ & 0 \\
\hline nASLR & $4.31 \pm 0.09 a$ & $4.25 \pm 0.11 \mathrm{ab}$ & $4.48 \pm 0.18 a$ & 0 \\
\hline
\end{tabular}

Abbreviations are as follows: ASB, autoclaved soil planted with basil; nASB, nonautoclaved soil planted with basil; ASLB, autoclaved soil inoculated with L. monocytogenes ATCC $19114^{\mathrm{T}}$ and planted with basil; nASLB, non-autoclaved soil inoculated with L. monocytogenes ATCC $19114^{\mathrm{T}}$ and planted with basil; ASR, autoclaved soil planted with rocket; nASR, non-autoclaved soil planted with rocket; ASLR, autoclaved soil inoculated with L. monocytogenes ATCC $19114^{\mathrm{T}}$ and planted with rocket; nASLR, non-autoclaved soil inoculated with L. monocytogenes ATCC $19114^{\mathrm{T}}$ and planted with rocket. Results indicate mean value \pm SD of four replicates of two independent experiments. Means with different letters within a column are significantly different $(P<0.05)$. 
inoculated and un-inoculated trials. To address these issues, RAPD profiles of all isolates collected from LSAB plates were compared to that of the type strain. As shown in Fig. 2, L. monocytogenes ATCC $19114^{\mathrm{T}}$ was recognized in all soil and seedling samples included in the four inoculated trials, while it was not found in the other four (un-inoculated) trials. However, six main RAPD patterns were obtained from presumptive Listeria spp. isolates associated with soil and seedling samples of the un-inoculated trials.

\subsection{Culture-independent analysis of soil and plant samples at harvest}

In order to recognize L. monocytogenes at species level, total DNA from soil samples and plants at harvest was analysed by DGGE (Fig. 3). The analysis included DNA from $L$. monocytogenes ATCC $19114^{\mathrm{T}}$ pure culture and that of an isolate collected at the $10^{8} \mathrm{CFU} \mathrm{g} \mathrm{dw}{ }^{-1}$ soon after soil inoculation. DGGE profiles (Fig. 3) showed the dominance of the inoculated strain at the beginning of the experimentation and confirmed the absence of L. monocytogenes on the surface of leaves of any trial at harvest. Moreover, it displayed the presence of this species also in the uninoculated trials, even those performed with autoclaved soil. The last results are not surprising, since DNA may be accessible even after the death of a given bacterium. However, the combination of data from DGGE and plate counts (Table 1) undoubtedly showed the absence of live L. monocytogenes in soil of ASB and ASR trials. For the reason reported above, it has to be excluded any contamination of the leaves of basil and rocket by L. monocytogenes during plant growth.

\section{Discussion}

The presence of $L$. monocytogenes in foods represents a dangerous threat for the human health (WHO/FNU/FOS, 1995). The transfer of this food-borne pathogen on the surface of vegetable leaves may occur in several ways and the contact with soil may play a defining role in this process, since L. monocytogenes is generally found in soil (Welshimer \& Donker-Voet, 1971). Many food-borne pathogens are transmitted from soil to fresh vegetables during the pre-harvest period, especially when the cultivation soil

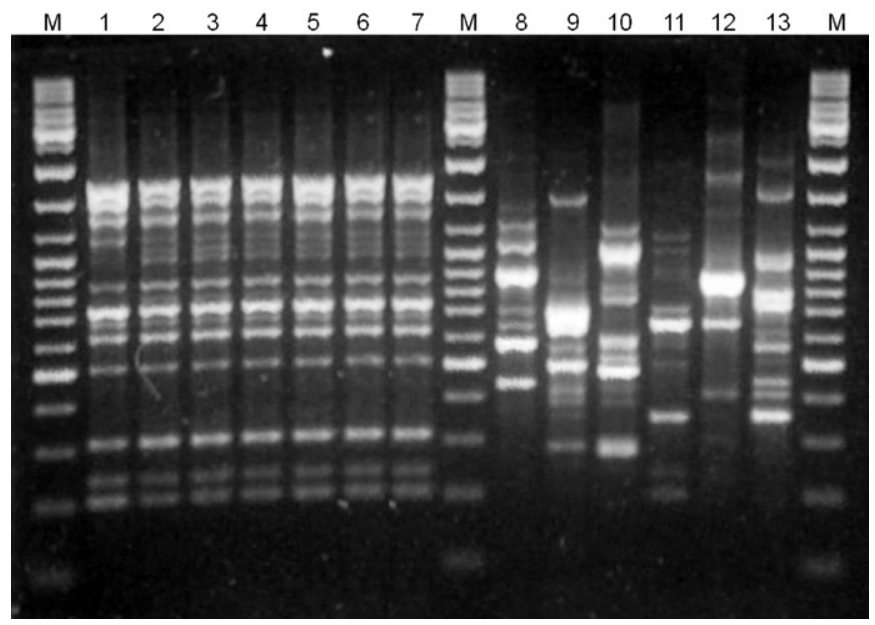

Fig. 2. RAPD-PCR profiles of colonies isolated from Listeria Selective Agar Base during the six weeks of cultivation of basil and rocket. Lanes: M, marker; 1, L. monocytogenes ATCC $19114^{\mathrm{T}} ; 2-3$, isolates from $10^{-8}$ dilution of inoculated autoclaved soil and inoculated non-autoclaved soil, respectively; $4-7$, isolates from $10^{-4}$ dilution of seedlings from ASLB, ASLR, nASLB and nASLR trial, respectively; 8-13, representative isolates from highest dilution of seedlings and soils of un-inoculated trails.

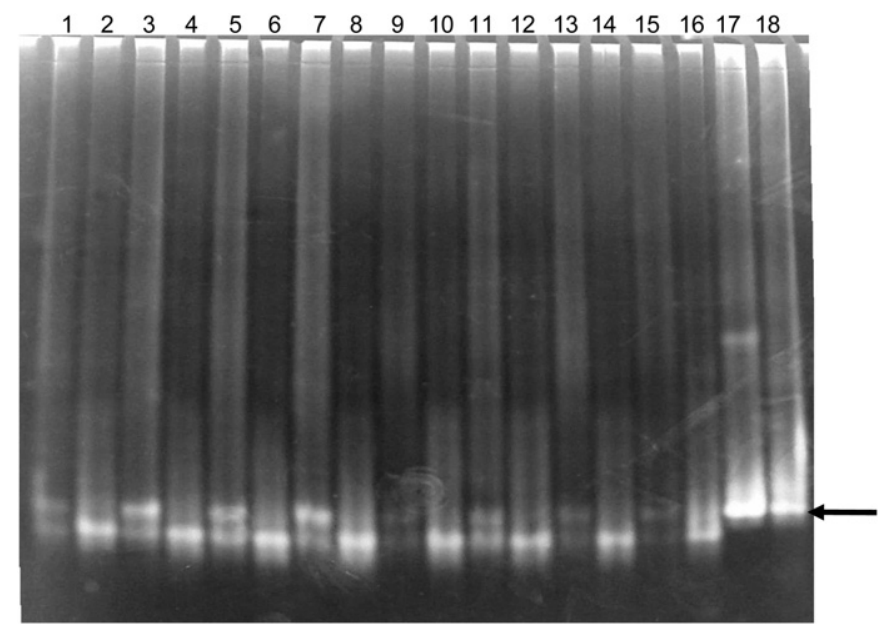

Fig. 3. DGGE profiles of soil and plant samples at harvest. Lanes: 1 , nASLR soil; 2 , nASLR plant; 3, ASLR soil; 4, ASLR plant; 5, nASLB soil; 6 , nASLB plant; 7, ASLB soil; 8 , ASLB plant; 9, nASR soil; 10, nASR plant; 11, ASR soil; 12, ASR plant; 13, nASB soil; 14 , nASB plant; 15, ASB soil; 16, ASB plant; 17, isolate collected after soil inoculation; 18 , L. monocytogenes ATCC $19114^{\mathrm{T}}$.

had been amended with manure-containing fertilizers, sewage sludge or the irrigation occurred with contaminated water (alGhazali \& al-Azawi, 1990; Beuchat, 1996; Doyle \& Erickson, 2008). The recent events concerning the contamination of different vegetable products by $E$. coli 0124 , that caused the death of several persons of different ages in Northern Europe (Moulson, 2011), have highlighted the importance of the safety characteristics of vegetables to be eaten raw, especially when cultivated under organic regimes which commonly employ manures as fertilizers.

This work was aimed to verify the hygienic safety of basil and rocket cultivated in soil contaminated by high levels of L. monocytogenes at sowing, simulating a massive contamination of soil. These two aromatic plants, with different growth habitus (rosette or caulescent plants), were chosen not only for their short crop cycle (1-2 months), during which $L$. monocytogenes may persist at high concentrations in soil and may be transferred at high numbers onto the surface of the leaves, but also because they do not generally undergo a thermal treatment before consumption.

The work was carried out with soil amended with inorganic fertilizer, in order to exclude the introduction of high concentrations of microorganisms with organic amendments. The pots were placed in a greenhouse during the spring season, at an average temperature of about $24.8{ }^{\circ} \mathrm{C}$. Four trials were followed for each leafy vegetable, including autoclaved and non-autoclaved, contaminated and un-inoculated, soil. Our data showed that the non-autoclaved un-inoculated soil contained about $10^{4} \mathrm{CFU} \mathrm{g} \mathrm{dw}{ }^{-1}$ of presumptive Listeria spp., from the beginning till the end of the experimentation, which lasted six weeks. The trials artificially contaminated with approximately $10^{9}$ CFU $\mathrm{g} \mathrm{dw}^{-1}$ of L. monocytogenes ATCC $19114^{\mathrm{T}}$ showed a decrease of this inoculums, which was more rapid, reaching lower levels, for the trials with non-autoclaved soil than those with autoclaved soil, both for basil and rocket. These results are in contrast with those reported by Jiang, Islam, Morgan, and Doyle (2004) which showed a longer survival of $L$. monocytogenes in manure-amended non-autoclaved soil than in manure-amended autoclaved soil. This difference in L. monocytogenes behaviour may be due to a different soil temperature, strain-specific characteristics, but it may be also explained by the fact that soil amended with manure and soil amended with inorganic fertilizer represent two distinct ecosystems, characterised by diverse $\mathrm{pH}$, water activity and oxidation-reduction potential. However, manure-amended soils 
are generally reported to allow the persistence of food-borne pathogens for several weeks (Franz et al., 2008; Johannessen et al., 2005). Kim and Jiang (2010) reported that L. monocytogenes in artificially contaminated autoclaved compost, kept in greenhouse during spring at an average temperature of $24.4{ }^{\circ} \mathrm{C}$, was characterised by a growth potential of $3.7 \log \mathrm{CFU} \mathrm{g}{ }^{-1}$ and a survival time $>28$ days; thus, our data confirmed this trend, since at the sixth week the concentration of $L$. monocytogenes was about $10^{5} \mathrm{CFU} \mathrm{g} \mathrm{dw}{ }^{-1}$. Furthermore, also Listeria innocua, whose survival abilities in soil are similar to L. monocytogenes (Girardin et al., 2005), can survive during spring season for more than six weeks as estimated in compost amended soil (Oliveira, Usall, Viñas, Solsona, \& Abadias, 2011).

Soil can be considered a hostile environment for microorganisms whose primary habitat is different, especially for those needing nutritionally rich matrices, such as foods. Hence, the microbes that may adapt to soil must overcome several hurdles (van Elsas, Tam, Finlay, Killham, \& Trevors, 2007). From this point of view, in our study, no major differences were found among different soil treatments. Thus, the reduction of $L$. monocytogenes inoculums till approximately $10^{5} \mathrm{CFU} \mathrm{g} \mathrm{dw}{ }^{-1}$ may be imputable to the effect of abiotic factors rather than microbial interaction, since the same trend was observed for all trials.

The agronomic conditions applied in this study included controlled watering of pots by sub-irrigation. This type of watering, applied to produce plants in pots, like basil sold in small pots, is useful to limit the risk of leaf contamination by soil particles that can occur when water hits the ground. Infact, surface irrigation was proved to be an important source of transfer of L. innocua from soil to lettuce leaves (Oliveira et al., 2011). Furthermore, to exclude any additional contamination of soil during watering, the water employed in this study was autoclaved before pouring. In these conditions, we evaluated exclusively the contribution of contaminated soil in the transmission of L. monocytogenes to the basil and rocket plants. After emergence, seedlings from inoculated trails were positive for the presence of the L. monocytogenes strain added to the soil, at levels of about $10^{4} \mathrm{CFU} \mathrm{g}{ }^{-1}$. Higher levels (about $10^{6} \mathrm{CFU} \mathrm{g}^{-1}$ ) of $L$. monocytogenes have been detected on seedlings of cress, lettuce, radish and spinach, analysed nine days postgermination, cultivated in gnotobiotic systems artificially inoculated (Jablasome, Warriner, \& Griffiths, 2005). In our study, also the seedlings from the un-inoculated trials showed the presence of presumptive Listeria spp., demonstrating that this bacterium is directly transferred to the surface of cotyledons.

In order to monitor the persistence of the strain added during the experimentation and to exclude cross-contamination of the uninoculated trials, the recognition of $L$. monocytogenes ATCC $19114^{\mathrm{T}}$ was performed by RAPD-PCR with DNA extracted from several colonies with similar appearance. This technique is generally applied for strain detection to evaluate the persistence of starter strains and/or changes in microbial composition of complex matrices (Giraffa \& Rossetti, 2004; Settanni, Massitti, Van Sinderen, \& Corsetti, 2005), but, to our knowledge, this is the first report on its application on the monitoring of $L$. monocytogenes in soil. RAPDPCR was also used for strain differentiation: six presumptive Listeria spp. strains were recognised as different from the inoculated strain ATCC $19114^{\mathrm{T}}$.

Although L. monocytogenes ATCC $19114^{\mathrm{T}}$ was found at about $10^{5} \mathrm{CFU} \mathrm{g} \mathrm{dw}{ }^{-1}$ in the soil of the inoculated trials and a slightly lower concentration of presumptive Listeria spp. was detected in the soil of the other trials, at harvest, no plant showed any listerial presence on the leaves, neither after direct plating nor after the application of the enrichment procedure. The presence of L. monocytogenes on the leaf surface was better investigated by a culture-independent approach using the DGGE technique. This tool allows the rapid detection of any accessible DNA, thus revealing the presence of a given microorganism, mostly at species level, without providing any indication on its live or dead state. DGGE technique is applied on the total DNA of a complex matrix without culturing the single organisms in purity (Muyzer, 1999). DGGE analysis showed that no past (at least no more accessible DNA was found) or present contamination by L. monocytogenes was detected on basil and rocket leaves of any trails. Furthermore, this technique showed that the listerial presence found in the soil of the un-inoculated trials was ascribable to the species L. monocytogenes.

Regarding the main objectives of this work, the conclusions drafted are as follows: L. monocytogenes may survive in soil amended with inorganic compounds during the whole crop cycle of rocket and basil; L. monocytogenes ATCC $19114^{\mathrm{T}}$ was still viable after six weeks in soil at an average temperature of $24.8^{\circ} \mathrm{C}$, even though at four orders of magnitude lower than inoculation; both culture-dependent and culture-independent detection demonstrated that, in this study, there had not been transfer of $L$. monocytogenes from contaminated soil to basil and rocket leaves, as estimated at harvest. Thus, for leafy vegetables, the crop management (sub-irrigation or drip irrigation, floating system cultivation, mulching, which separates the soil from leaves, etc.) might limit or eliminate the risks of pathogenic microbial transfer from soil to leaves, which, however may occur in the open field due to the splash effect of raindrops or overhead irrigation. Works are being prepared in order to evaluate the contamination caused by the splash effect in the growing field.

\section{References}

al-Ghazali, M. R., \& al-Azawi, S. K. (1990). Listeria monocytogenes contamination of crops grown on soil treated with sewage sludge cake. Journal of Applied Bacteriology, 69, 642-647.

Beuchat, L. R. (1996). Pathogenic microorganisms associated with fresh produce Journal of Food Protection, 59, 204-216.

Beuchat, L. R., \& Ryu, J. H. (1997). Produce handling and processing practices. Emerging Infectious Diseases, 3, 459-465.

Bianco, V. V. (1995). Rocket, an ancient underutilized vegetable crop and its potential. In S. Padulosi (Ed.), Rocket genetic resources network. Report of the first meeting, Lisbon, Portugal, 13-15 November 1994. Rome: International Plant Genetic Resources Institute.

Breer, C., \& Baumgartner, A. (1992). Occurrence and behavior of Listeria monocytogenes on salads, vegetables, and in fresh vegetable juices. Archiv fur Lebensmittelhygiene, 43, 108-110.

Buck, J. W., Walcott, R. R., \& Beuchat, L. R. (2003). Recent trends in microbiological safety of fruits and vegetables (online). Plant Health Progress. doi:10.1094/PHP2003-0121-01-RV.

Cordano, A. M., \& Jacquet, C. (2009). Listeria monocytogenes isolated from vegetable salads sold at supermarkets in Santiago, Chile: prevalence and strain characterization. International Journal of Food Microbiology, 132, 176-179.

D’Anna, F., Miceli, A., \& Vetrano, F. (2003). First results on floating system cultivation of Eruca sativa L. Acta Horticulturae, 609, 361-364.

DeWaal, C. S., \& Bhuiya, F. (2007). Outbreaks by the numbers: Fruits and vegetables. 1990-2005. Available from http://www.cspinet.org/foodsafety/IAFPPoster.pdf Accessed 1.7.11.

Doyle, M. P., \& Erickson, M. C. (2008). Summer meeting 2007 - the problems with fresh produce: an overview. Journal of Applied Microbiology, 105, 317-330.

Drevets, D. A., \& Bronze, M. S. (2008). Listeria monocytogenes: epidemiology, human disease, and mechanisms of brain invasion. FEMS Immunology and Medicine Microbiology, 53, 151-165

European Water Framework Directive. (2000). European water framework directive (2000/60/EC), 2000. http://ec.europa.eu/environment/water/water-framework/ index_en.html Accessed 1.10.11.

Farber, J. M. (2000). Present situation in Canada regarding Listeria monocytogenes and ready-to-eat seafood products. International Journal of Food Microbiology, 62, 247-251.

Forslund, A., Ensink, J. H. J., Battilani, A., Kljujev, I., Gola, S., Raicevic, V., et al. (2010) Faecal contamination and hygiene aspect associated with the use of treated wastewater and canal water for irrigation of potatoes (Solanum tuberosum). Agricultural Water Management, 98, 440-450.

Franz, E., Semenov, A. V., Termorshuizen, A. J., de Vos, O. J., Bokhorst, J. G., \& van Bruggen, A. H. C. (2008). Manure-amended soil characteristics affecting the survival of E. coli 0157:H7 in 36 Dutch soils. Environmental Microbiology, 10, 313-327.

Giannino, M. L., Marzotto, M., Dellaglio, F., \& Feligini, M. (2009). Study of microbial diversity in raw milk and fresh curd used for Fontina cheese production by 
culture-independent methods. International Journal of Food Microbiology, 130, $188-195$.

Giraffa, G., \& Rossetti, L. (2004). Monitoring of the bacterial composition of dairy starter cultures by RAPD-PCR. FEMS Microbiology Letters, 237, 133-138.

Girardin, H., Morris, C. E., Albagnac, C., Dreux, N., Glaux, C., \& Nguyen-The, C. (2005). Behaviour of the pathogen surrogates Listeria innocua and Clostridium sporogens during production of parsley in fields fertilized with contaminated amendments. FEMS Microbiology Ecology, 54, 287-295.

Goulet, V., Hedberg, C., Le Monnier, A., \& de Valk, H. (2008). Increasing incidence of listeriosis in France and other European countries. Emerging Infectious Diseases, 14, 734-740.

Hamilton, A. J., Boland, A. M., Stevens, D., Kelly, J., Radcliffe, J., Ziehrl, A., et al. (2005). Position of the Australian horticultural industry with respect to the use of reclaimed water. Agricultural Water Management, 71, 181-209.

Jablasone, J., Warriner, K., \& Griffiths, M. (2005). Interactions of Escherichia coli 0157:H7, Salmonella typhimurium and Listeria monocytogenes plants cultivated in a gnotobiotic system. International Journal of Food Microbiology, 99, 7-18.

Jayasinghe, C., Gotoh, N., Aoki, T., \& Wada, S. (2003). Phenolics composition and antioxidant activity of sweet basil (Ocimum basilicum L.). Journal of Agricultural and Food Chemistry, 51, 4442-4449.

Jiang, X., Islam, M., Morgan, J., \& Doyle, M. P. (2004). Fate of Listeria monocytogenes in bovine manure-amended soil. Journal of Food Protection, 67, 1676-1681.

Johannessen, G. S., Bengtsson, G. B., Heier, B. T., Bredholt, S., Wasteson, Y., \& Rorvik, L. M. (2005). Potential uptake of Escherichia coli 0157:H7 from organic manure into crisphead lettuce. Applied and Environmental Microbiology, 71, 2221-2225.

Kim, J., \& Jiang, X. (2010). The growth potential of Escherichia coli 0157:H7, Salmonella spp. and Listeria monocytogenes in dairy manure-based compost in a greenhouse setting under different seasons. Journal of Applied Microbiology, 109, 2095-2104

Little, C. L., Taylor, F. C., Sagoo, S. K., Gillespie, I. A., Grant, K., \& McLauchlin, J. (2007) Prevalence and level of Listeria monocytogenes and other Listeria species in retail pre-packaged mixed vegetable salads in the UK. Food Microbiology, 24, 711-717.

Martínez-Sánchez, A., Allende, A., Bennett, R. N., Ferreres, F., \& Gil, M. I. (2006) Microbial, nutritional and sensory quality of rocket leaves as affected by different sanitizers. Postharvest Biology and Technology, 42, 86-97.

Militello, M., Settanni, L., Aleo, A., Mammina, C., Moschetti, G., Giammanco, G. M. et al. (2011). Chemical composition and antibacterial potential of Artemisia arborescens L. essential oil. Current Microbiology, 62, 1274-1281.

Moulson, G. (2011). E. coli death toll up to at least 47. Associated Press.

Muyzer, G. (1999). DGGE/TGGE a method for identifying genes from natural ecosystems. Current Opinion in Microbiology, 2, 317-322.

Niessen, S., Mcleod, I., \& Yates, J. R. (2005). Identification of novel proteins complexes and protein-protein interaction by mass spectrometry. In
E. A. Golemis, \& P. D. Adams (Eds.), Protein-protein interaction: A molecular cloning manual (pp. 329-354). New York: Cold Spring Harbor Press.

Oliveira, M., Usall, J., Viñas, I., Solsona, C., \& Abadias, M. (2011). Transfer of Listeria innocua from contaminated compost and irrigation water to letture leaves. Food Microbiology, 28, 590-596.

Sagoo, S. K., Little, C. L., Ward, L., Gillespie, I. A., \& Mitchell, R. T. (2003). Microbiological study of ready-to-eat salad vegetables from retail establishments uncovers a national outbreak of salmonellosis. Journal of Food Protection, 66, 403-409.

Scott, C. A., Faruqui, N. I., \& Raschid-Sally, L. (2004). Wastewater use in irrigated agriculture: management challenges in developing countries. In A. Scott, N. I. Faruqui, \& L. Raschid-Sally (Eds.), Wastewater use in irrigated agriculture: Confronting the livelihood and environmental realities (pp. 1-10). Oxfordshire: CABI Publishing.

Settanni, L., Massitti, O., Van Sinderen, D., \& Corsetti, A. (2005). In situ activity of a bacteriocin-producing Lactococcus lactis strain. Influence on the interactions between lactic acid bacteria during sourdough fermentation. Journal of Applied Microbiology, 99, 670-681.

Sivapalasingam, S., Friedman, C. R., Cohen, L., \& Tauxe, R. V. (2004). Fresh produce: a growing cause of outbreaks of foodborne illness in the United States, 1973 through 1997. Journal of Food Protection, 67, 2342-2353.

Stenlid, J., Karlsson, J. O., \& Hogberg, N. (1994). Intra-specific genetic variation in Heterobasidium annosum revealed by amplification of minisatellite DNA. Mycological Researches, 98, 57-63.

Toze, S. (2006). Reuse of effluent water-benefits and risks. Agricultural Water Management, 80, 147-159.

Valero, M., Hernández-Herrero, L. A., \& Giner, M. J. (2007). Survival, isolation and characterization of a psychrotrophic Bacillus cereus strain from a mayonnaisebased ready-to-eat vegetable salad. Food Microbiology, 24, 671-677.

van Elsas, J. D., Tam, L., Finlay, R. D., Killham, K., \& Trevors, J. T. (2007). Microbial interactions in soil. In J. D. van Elsas, J. K. Jansson, \& J. T. Trevors (Eds.), Modern soil microbiology (pp. 177-210). Boca Raton: CRC Press.

Walter, J., Tannock, G. W., Tilsala-Timisjarvi, A., Rodtong, S., Loach, D. M., Munro, K., et al. (2000). Detection and identification of gastrointestinal Lactobacillus species by using denaturing gradient gel electrophoresis and species-specific PCR primers. Applied and Environmental Microbiology, 66, 297-303.

Welshimer, H. J., \& Donker-Voet, J. (1971). Listeria monocytogenes in nature. Applied Microbiology, 21, 516-519.

WHO/FUN/FOS. (1995). Food technologies and public health. http://www.who.int/ foodsafety/publications/fs_management/en/foodtech.pdf Accessed 1.10.11.

Zapparoli, G., Torriani, S., \& Dellaglio, F. (1998). Differentiation of Lactobacillus sanfranciscensis strains by randomly amplified polymorphic DNA and pulsedfield gel electrophoresis. FEMS Microbiology Letters, 166, 324-332. 